\title{
A study on the strength of an armour-grade aluminum under high strain-rate loading
}

\author{
G. J. Appleby-Thomas ${ }^{\text {a) }}$ and P. J. Hazell ${ }^{\text {b) }}$ \\ Cranfield Defence and Security, Cranfield University, Shrivenham, Swindon SN6 8LA, United Kingdom
}

(Received 18 March 2010; accepted 21 April 2010; published online 18 June 2010)

\begin{abstract}
The aluminum alloy 5083 in tempers such as H32 and H131 is an established light-weight armour material. While its dynamic response under high strain-rates has been investigated elsewhere, little account of the effect of material orientation has been made. In addition, little information on its strength under such loadings is available in the literature. Here, both the longitudinal and lateral components of stress have been measured using embedded manganin stress gauges during plate-impact experiments on samples with the rolling direction aligned both orthogonal and parallel to the impact axis. The Hugoniot elastic limit, spall, and shear strengths were investigated for incident pressures in the range 1-8 GPa, providing an insight into the response of this alloy under shock loading. Further, the time dependence of lateral stress behind the shock front was investigated to give an indication of material response. [doi:10.1063/1.3431346]
\end{abstract}

\section{INTRODUCTION}

Applications ranging from satellite shielding to automotive crash-protection require knowledge of the shock response of constituent materials. Consequently, information on the high strain-rate response of materials is essential to fully understand their behavior under impact. Unfortunately, impact phenomena are by their nature complex. Both targets and projectiles typically possess extended three-dimensional structures and impacts are seldom orthogonal. Consequently, simplified experiments which allow a constitutive relationship for individual materials to be established are normally undertaken to provide data which is then used to model more physically realistic (and complex) impact events. At strainrates $\geq 10^{6} / \mathrm{s}$, plate-impact experiments provide a method of establishing a one-dimensional (1D) state of strain in a target material. Impact of a flat/parallel flyer plate driven by a compressed gas/powder gun generates a compressive shock in a target material. Inertial confinement results in a 1D state of strain maintained within the target until relieved by release waves from external edges. The resultant shock is monitored by instrumentation (such as embedded stress gauges), allowing the following key experimental parameters to be determined: the shock velocity in the target material, $\mathrm{U}_{\mathrm{S}}$; the continuum mass/particle velocity behind the shock front, $\mathrm{u}_{\mathrm{P}}$, and; the equilibrium longitudinal (Hugoniot) stress established behind the shock, $\sigma_{\mathrm{X}}$. Hugoniot relationships (describing the physical states a shocked material passes through) in $\mathrm{U}_{\mathrm{S}}-\mathrm{u}_{\mathrm{P}}$ and $\sigma_{\mathrm{X}}-\mathrm{u}_{\mathrm{P}}$ space may then be established, and the remaining shock parameters (density and internal energy) derived via a series of relations known as the Rankine-Hugoniot equations. ${ }^{1} \quad$ When combined with

\footnotetext{
${ }^{\text {a) }}$ Author to whom correspondence should be addressed. Tel.: +44 (0) 1793 784192. Electronic mail: g.applebythomas@ cranfield.ac.uk.

b) Also at Institute of Shock Physics, Royal School of Mines, Prince Consort Road, Imperial College London, London, SW7 2BP.
}

strength data, the $\mathrm{U}_{\mathrm{S}}, \mathrm{u}_{\mathrm{P}}, \sigma_{\mathrm{X}}$ behavior under shock provides sufficient information to model the materials hydrodynamic response. ${ }^{1}$

Due to their combination of low densities with high strengths, aluminum alloys have found a substantial niche in armour applications. This has led to extensive investigation of the high strain-rate response of principal aluminum alloys, with a wide variety of information available in the literature. For example, Huang and $\mathrm{Asay}^{2}$ carried out an in-depth study of the high stain-rate response of the aluminum alloy 6061T6. A combination of shock/reshock and shock/release impact experiments designed to allow estimation of compressive strength under shock loading were used to investigate the compression of Al 6061-T6 with well characterized grain-sizes of $<5,30$, and $50 \mu \mathrm{m}$. In all cases both reloading and release were preceded by a complex loading comprising an initially elastic region followed by a mixed elastic-plastic response, referred to as quasielastic behavior. ${ }^{2}$ This quasielastic response was noted to differ from conventional plastic reloading where the resultant shock state lies on the yield surface. Two possible mechanisms for such behavior in the reloading experiments were considered: (1) timedependant yielding, or; (2) a hardening phenomena leading to a shear stress state that lay within the yield surface. This second explanation (e.g., strengthening under shock) was adopted, backed by an observed increase in the gradient of the quasielastic ramp with impact stress. ${ }^{2}$ Comparison to the response of commercially available grades of pure aluminum with grain-sizes of 180 and $300 \mu \mathrm{m}$ exhibiting very low impurity levels showed that, unlike low strain-rate situations, the quasielastic element of loading was not affected by impurity concentrations. No significant differences between the traces for $<5$ and $30 \mu \mathrm{m}$ grain-sizes were observed when the response of the aluminum targets with differing grainsizes was compared, with only subtle changes apparent for a grain-size of $50 \mu \mathrm{m}$. These results were taken to imply that yield strength under shock is independent of grain-size (e.g., that the Hall-Petch relationship ${ }^{3}$ does not apply in $\mathrm{Al} 6061$ at 
high strain-rates). Derived shear strengths were observed in all cases to increase in magnitude with impact stress. However, while the rate of increase was constant for the different microstructures/grades of $\mathrm{Al}$ considered, in terms of the absolute magnitude, strong correlation with the initial yield strength of the material in question was found.

Millett et al. ${ }^{4}$ studied a very similar alloy, Al 6082-T6. Lateral T-type manganin stress gauges incorporated into the center of sectioned Al 6082-T6 targets were used to monitor changes in shear strength behind the shock front. As with Al 6061-T6, ${ }^{2}$ evidence of plastic deformation increasing with impact stress was apparent. However, little evidence of postshock hardening was detected in subsequent material analysis. Additionally, lateral gauge traces were found to be relatively flat, taken to suggest that little additional workhardening occurred following shock arrival. The lack of significant strengthening under shock loading was attributed to the presence of dispersed intermetallic particles which acted to suppress the formation of dislocation cells.

In line with the investigation of the effects of grain-size on material strength under shock loading conducted by Huang and Asay, ${ }^{2}$ other authors have considered the influence of different microstructural elements on the high strainrate response on aluminum. For example, Millett et al. ${ }^{5}$ used longitudinal manganin stress gauges mounted on the rear surface of samples cut with the rolling direction normal (the short-transverse direction) parallel to the impact axis to investigate the Hugoniot elastic limit (HEL) and spall phenomena of $\mathrm{Al} 7017$ under a number of aging conditions. Interestingly, while the HEL was found to be dependent on the heat treatment of the target material, spall strength was shown to be independent-implying that it was primarily influenced by a variable independent of the treatment route (in this case, this was assumed to be the presence of intermetallic particles which acted as the site for subsequent material failure). It was also noted that spall in recovered samples appeared to initiate around intermetallic $(\mathrm{Fe}, \mathrm{Mn}) \mathrm{Al}_{6}$ inclusions and that, unexpectedly, cracks formed along grain boundaries at the spall plane did not appear interconnected despite clear spall pullback signals. This latter phenomenon was attributed to the nature of the manganin stress gauges employed which acted to average the effect of spall at localized sites over a $20 \mathrm{~mm}^{2}$ area, producing a discrete response. In similar work, the effect of grain orientation (e.g., orientation direction parallel to the impact axis) on the HEL and spall strength of the alloy Al 7010-T6 was investigated by Edwards et al. ${ }^{6}$ using symmetric (Al flyer) plate-impact experiments. While elastic properties were found to be essentially independent of orientation, the HEL was found to be higher in the longitudinal direction than the short-transverse direction $(0.39 \mathrm{GPa}$ and $0.33 \mathrm{GPa}$, respectively, independent of impact velocity/pressure). Similar spall strengths for targets with differing impact face microstructural textures were observed at an impact velocity of $450 \mathrm{~m} / \mathrm{s} ; 1.00$ and $1.19 \mathrm{GPa}$ in the longitudinal/short-transverse directions, respectively. However, at an elevated impact velocity of $895 \mathrm{~m} / \mathrm{s}$ values of $1.44 / 0.58 \mathrm{GPa}$ in the longitudinal/short-transverse directions were noted. The lower spall strength in the short-transverse direction was unexpected and further work was suggested as only a single test was used to establish this response.

The wrought alloy Al 5083 has been adopted for armour applications (e.g., tempers H32, H131, and H116) due to its suitability for rolling ${ }^{7,8}$ and its combination of low density, high strength (due to a high $\mathrm{Mg}$ content) and resistance to corrosion. ${ }^{9,10}$ Some studies into the relatively low strain-rate response of Al 5083 have been undertaken. For example, Kaibyshev et al. ${ }^{11}$ characterized an Al 5083 alloy (modified with an additional 0.2 wt $\% \mathrm{Zr}$ in order to alter properties such as creep resistance) at strain-rates of up to $6 \times 10^{-2} / \mathrm{s}$ using a universal testing machine, allowing engineering stress-strain curves to be established in this regime. However, such data is not directly applicable to impact phenomena where significantly higher strain-rates can lead to hydrodynamic behavior. To date, the majority of the investigations into loading of Al 5083 have been designed to investigate armour concepts or to provide data for model evaluation; consequently, this work has largely involved ballistic tests. ${ }^{7-9}$ The main investigation of the dynamic response of Al 5083 at elevated strain-rates (rather than simply ballistic impact tests) was conducted by Boteler and Dandekar. ${ }^{10}$ Plateimpact experiments were conducted on two armour-grade tempers of Al5083, H131 (strain-hardened) and H32 (strainhardened/partially annealed), at impact stresses of 1.5-8.1 $\mathrm{GPa}$, with results compared to higher pressure data and information on the behavior of Al 5083-O (fully annealed) previously reported. These experiments, which used a velocity interferometer system for any reflector (VISAR) to monitor the target rear surface, allowed both Hugoniot equationsof-state and HELs to be established. Linear equations-ofstate with the general form $\mathrm{U}_{\mathrm{S}}=\mathrm{c}_{0}+\mathrm{Su}_{\mathrm{P}}$ were established for both tempers and were found to be comparable. The constants $\mathrm{S}$ (dimensionless) and $\mathrm{c}_{0}$ (millimeter per microsecond) were found to be similar for both tempers, with values of $\mathrm{S}=5.29 / 5.14$ and $\mathrm{c}_{0}=1.40 / 1.267$ for $\mathrm{H} 131 / \mathrm{H} 32$, respectively. HELs were also measured; for H131 an average of $0.57 \mathrm{GPa}$ was found, while for the partially annealed H32 a lower value of $0.44 \mathrm{GPa}$ was measured. Subsequent analysis of this data by Boteler and Dandekar ${ }^{12}$ has allowed determination of an average spall strength for Al 5083 H131 of $0.936 \pm 0.005 \mathrm{GPa}$. This was significantly below that for the fully annealed Al 5083-O temper (c.1.6 GPa). However, unlike Al 7010-T6 investigated by Edwards et al., ${ }^{6}$ no dependence on impact parameters was detected.

Only one paper is apparent in the literature which deals with the evolution of lateral stress in Al 5083 under shock loading. ${ }^{13}$ In this paper, embedded manganin lateral stress gauges were used to monitor lateral stress development both at and following behind shock front arrival within Al 5083 (H32) targets. Based on comparison to the known Al 5083 Hugoniot relationship described elsewhere, ${ }^{10}$ evidence of an increase in shear strength with increasing impact stress was presented. However, no time-dependant strengthening behind the shock was detected. The intercept between a plot of the theoretical elastic response and the measured change in shear strength with impact stress was taken as an estimate of the HEL; a value of c. $0.47 \mathrm{GPa}$ was found, in good agreement with results presented elsewhere in the literature. ${ }^{10}$ 
TABLE I. Key elastic properties of Al 5083 H32.

\begin{tabular}{cccccc}
\hline \hline $\begin{array}{c}\mathrm{c}_{\mathrm{L}} \\
(\mathrm{mm} / \mu \mathrm{s})\end{array}$ & $\begin{array}{c}\mathrm{c}_{\mathrm{S}} \\
(\mathrm{mm} / \mu \mathrm{s})\end{array}$ & $\begin{array}{c}\mathrm{c}_{0} \\
(\mathrm{~mm} / \mu \mathrm{s})\end{array}$ & $\begin{array}{c}\rho_{0} \\
\left(\mathrm{~g} / \mathrm{cm}^{3}\right)^{a}\end{array}$ & $\begin{array}{c}\mathrm{E} \\
(\mathrm{GPa})\end{array}$ & $\nu$ \\
\hline $6.32 \pm 0.10$ & $3.11 \pm 0.10$ & $5.19 \pm 0.10$ & $2.668 \pm 0.004$ & $69.3 \pm 3.5$ & $0.34 \pm 0.02$ \\
\hline \hline
\end{tabular}

${ }^{\mathrm{a}}$ Reference 10 .

While there are a number of important bodies of work dealing with the dynamic behavior of armour grades of the important $\mathrm{Al}$ alloy 5083 (in particular, work by Boteler and Dandekar ${ }^{10}$ ), it is apparent that only minimal information on the strength of Al 5083 under shock loading has been presented. Such information is of particular relevance to the key area of armour applications due to the insight into ballistic response provided by a knowledge of shear strength. Consequently, this paper builds on the results presented by Appleby-Thomas et al., ${ }^{13}$ in particular investigating the orientation-dependence of lateral stress behavior/ strengthening behavior in an armour-grade $\mathrm{Al}, 5083 \mathrm{H} 32$. To complement work presented by Boteler and Dandekar, ${ }^{12}$ the spall strength of this alloy is investigated (here as a function of both grain orientation and impact stress), while symmetric and asymmetric plate-impact tests are undertaken to refine the published Al 5083 H32 Hugoniot.

\section{MATERIAL PROPERTIES}

The aluminum alloy ( $\mathrm{Al} 5083 \mathrm{H} 32$ ) investigated in this paper was sourced from armour material that would otherwise have been used in an armoured fighting vehicle. Its principal alloying elements are manganese and magnesium (0.4-1.0 wt \% and 4.0-4.9 wt \%, respectively); manganese increases strength, although simultaneously acting to limit ductility, while magnesium acts to increase strength without any detrimental effects on ductility. ${ }^{10}$ An average Vickers hardness of $97.1 \pm 2.0 \mathrm{Hv}$ was found on material testing, in good agreement with the value of $98 \mathrm{Hv}$ for AL $5083 \mathrm{H} 32$ quoted elsewhere. ${ }^{14} \mathrm{~A}$ Panametrics 5077PR pulse receiver in the pulse-echo configuration was used, in conjunction with appropriate Panametrics $5.0 \mathrm{MHz}$ transducers, to measure the longitudinal and shear wave sound speeds $\left(\mathrm{c}_{\mathrm{L}}\right.$ and $\mathrm{c}_{\mathrm{S}}$, respectively) in the $\mathrm{Al}$ used as target material. The results, together with key calculated elastic properties based on the known density, $\rho_{0}$, of Al 5083, ${ }^{10}$ are presented in Table I. Calculated elastic properties included are the bulk sound speed $\mathrm{c}_{0}$, the Poisson's ratio $\nu$, and the Young's modulus E. One point of note is the good agreement between the calculated bulk sound speed and the value for Al 5083 of $\mathrm{c}_{0}$ $=5.36 \pm 0.02 \mathrm{~mm} / \mu \mathrm{s}$ found by Boteler and Dandekar. ${ }^{10}$

\section{EXPERIMENTAL}

Plate-impact experiments ${ }^{1,10,15,16}$ were used to determine dynamic properties of the target material. A $\varnothing 50 \mathrm{~mm}$ bore, 5 $\mathrm{m}$ barrel, single-stage gas-gun was used for all experiments. ${ }^{17}$ Lateral and longitudinal manganin stress gauges, of types LM-SS-125CH-048 and J2M-SS-580SF025 respectively (both manufactured by Vishay MicroMeasurements), were employed as appropriate. Longitudinal gauges were interpreted according to the impedance match- ing technique, ${ }^{1,18}$ with a modified form accounting for both the elastic-plastic response of manganin ${ }^{19}$ and its pressuredependant behavior below its elastic limit ${ }^{20}$ employed where lateral gauges were used. Target material was cut into (approximately) $10 \mathrm{~mm}$ thick plates, with square (approximately) $60 \times 60 \mathrm{~mm}^{2}$ faces, a size judged sufficient to avoid the influence of release waves from the target edge during impact experiments. These impact faces were subsequently machined to a surface roughness of $<5 \mu \mathrm{m}$. In the case of lateral gauge-based experiments, the targets were sectioned into $30 \times 60 \mathrm{~mm}^{2}$ pieces. The contact faces between the two targets halves were then machined to a similar finish. Manganin stress gauges of appropriate types were introduced either in front/behind or in the center (in the case of lateral gauges) of targets. In most cases $25 \mu \mathrm{m}$ thick Mylar was employed to insulate the gauges from the surrounding material and to protect them for a sufficient duration to allow the incident shock to fully propagate through the target. However for experiments designed to measure the spall strength, the rear surface gauges employed required a greater degree of protection in order to allow detection of the spall pullback signal (the reflection from the spall plane at the target rear surface $\left.^{5,16}\right)$. Consequently, c. $1 \mathrm{~mm}$ thick Perspex was employed for the purpose of gauge protection in such experiments. For both the lateral and longitudinal targets, all components were bonded together using a slow cure epoxy (Loctite $0151 \mathrm{HYSOL}^{\circledR}$ Epoxi-Patch $^{\circledR}$ Adhesive), before being left overnight in appropriate proprietary clamping arrangements to ensure planarity was maintained. Where longitudinal gauges were employed these were either placed both sides of homogenous targets of $\mathrm{Al} 5083$ or adhered to the rear of lateral gauge targets. Typical target arrangements (excluding the Mylar inserted either side of lateral gauges in order to maintain clarity) are shown in Fig. 1(a) (longitudinal gauge only) and Fig. 1(b) (lateral plus longitudinal gauges), respectively.

The shock velocity $\mathrm{U}_{\mathrm{S}}$ may be directly calculated from a knowledge of gauge separation and shock arrival times for the two gauges shown in Fig. 1(a). The impedance matching technique ${ }^{1,15,18}$ normally employs identical flyer and coverplate materials. Where this is the case, by definition, the particle velocity in the flyer, cover and target materials will be the same. A Rayleigh line for the aluminum target ( $\mathrm{P}$ $=\rho_{0} \mathrm{U}_{\mathrm{S}} \mathrm{u}_{\mathrm{P}}$, with $\rho_{0}$ the density of $\mathrm{Al} 5083$ detailed in Table I) can then be established. Well-characterized flyer materials with an established polynomial particle velocity-pressure $\left(\mathrm{u}_{\mathrm{P}}-\mathrm{P}\right)$ Hugoniot relationship are employed. The intercept of the target Rayleigh line and an inverted form of the known flyer $\mathrm{u}_{\mathrm{P}}-\mathrm{P}$ polynomial Hugoniot, recentered on the velocity of impact, then allows calculation of the particle velocity.

Once assembled, targets were mounted on a target ring 


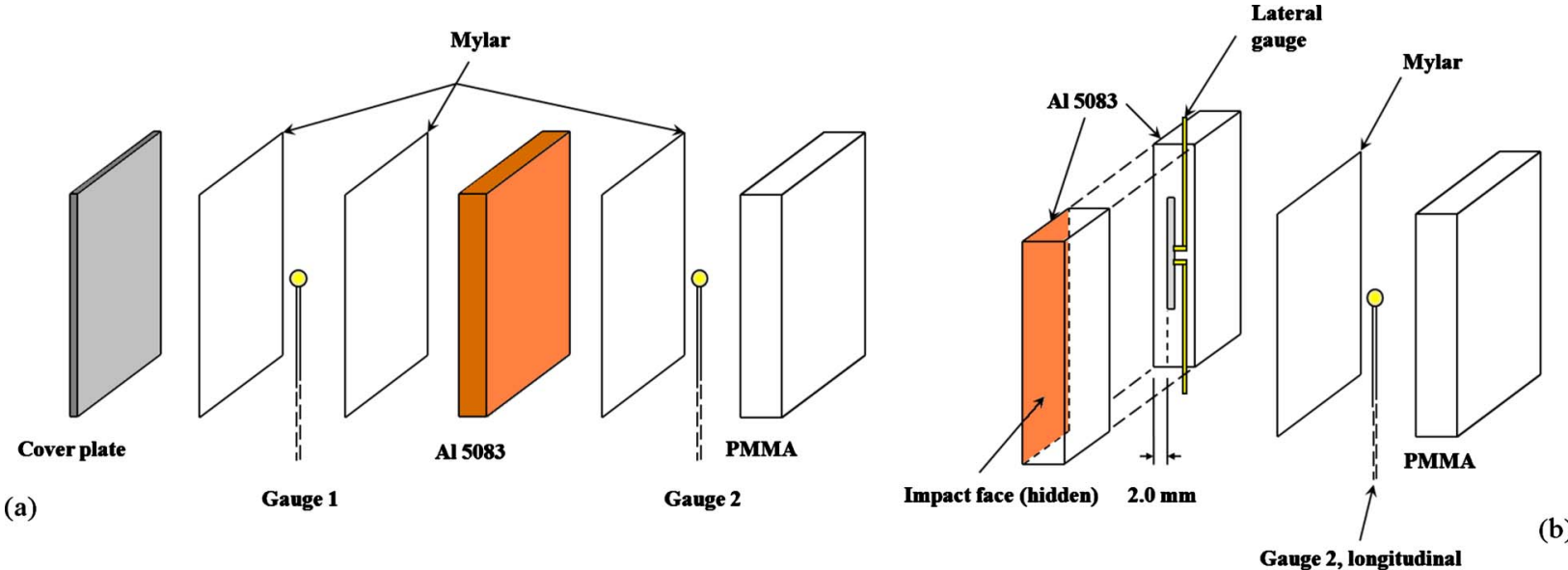

(b)

FIG. 1. (Color online) Typical plate-impact experimental arrangements: (a) longitudinal-only case; (b) lateral/longitudinal case.

containing a pair of trigger pins to allow signal recording on an attached $1 \mathrm{GHz}$ oscilloscope to be initiated. In turn, this ring was placed on a sacrificial barrel extension, with an attached set of pins which were sequentially shorted prior to impact to provide a direct measure of the projectile impact velocity. Projectiles consisted of an acetal sabot-backed flyer plate machined to an impact surface roughness of $<5 \mu \mathrm{m}$, whose material was chosen according to the impedance matching technique in order to achieve the desired experimental conditions for a given test. This arrangement is shown schematically for the lateral gauge only case in Fig. 2.

\section{RESULTS AND DISCUSSION}

\section{A. Experimental results}

A series of lateral/longitudinal and longitudinal gaugeonly shots were undertaken to investigate both lateral and shear stress/strength behavior in the $\mathrm{Al}$ armour material. In addition, a series of plate-impact experiments were conducted to confirm that the $\mathrm{Al}$ armour material was indeed H32 grade. Experimental details, together with resultant particle velocity $\left(\mathrm{u}_{\mathrm{P}}\right)$, shock velocity $\left(\mathrm{U}_{\mathrm{S}}\right)$, Hugoniot stress $\left(\sigma_{\mathrm{X}}\right)$, lateral stress $\left(\sigma_{\mathrm{Y}}\right)$, spall strength $\left(\sigma_{\text {spall }}\right)$, and HEL stress $\left(\sigma_{\mathrm{HEL}}\right)$ values as appropriate are summarized in Table II. Shock and particle velocities were established based on the impedance matching technique in the manner described previously. Hugoniot and lateral stresses were measured from

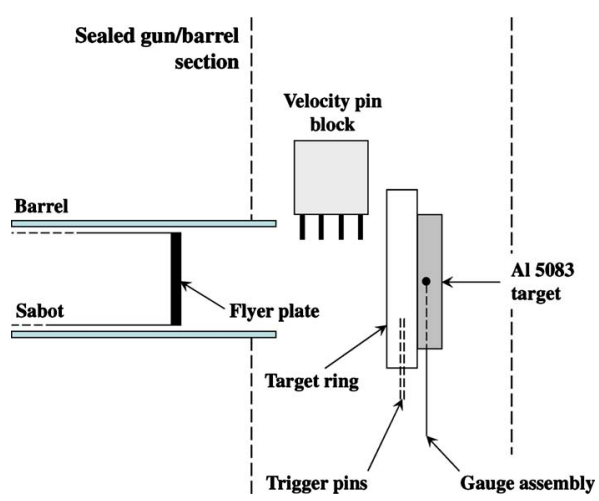

FIG. 2. (Color online) Schematic illustration of typical lateral gauge only experimental setup. the beginning of calibrated longitudinal and lateral stress plateaus established immediately following shock arrival, respectively. Finally, spall strengths and HEL stresses were directly measured from appropriate features on recorded rearsurface longitudinal gauge traces ${ }^{15}$ (pullback signals and changes in gradient during the initial ring-up on shock arrival, respectively). Where rear surface gauges were employed to measure spall strengths and HEL values, the quoted values of $\sigma_{\mathrm{X}}$ in Table II were converted from those directly measured in the poly(methyl methacrylate) (PMMA) backing according to Eq. (1). ${ }^{15}$

$$
\sigma_{\mathrm{Al}}=\frac{1}{2} \frac{\left(Z_{\mathrm{Al}}+Z_{\mathrm{PMMA}}\right)}{Z_{\mathrm{PMMA}}} \sigma_{\mathrm{PMMA}},
$$

where $\sigma_{\mathrm{Al}}$ is the stress in the $\mathrm{Al}$ alloy, $\sigma_{\mathrm{PMMA}}$ is the stress in the PMMA, $Z_{\mathrm{Al}}$ the impedance of the $\mathrm{Al}$, and $\mathrm{Z}_{\mathrm{PMMA}}$ the impedance of the PMMA. In general, $Z=\rho_{0} \mathrm{U}_{\mathrm{s}}$, where $\rho_{0}$ is the material density and $U_{s}$ is the wave velocity in the PMMA, calculated from the known $\mathrm{U}_{\mathrm{S}}-\mathrm{u}_{\mathrm{P}}$ Hugoniot for PMMA based on the measured particle velocity (continuity dictates that $\mathrm{u}_{\mathrm{P}}$ will be equal in the target and the PMMA backing).

Typical traces for both the front and rear gauges from the $672 \mathrm{~m} / \mathrm{s}$ shot in Table II are shown in Fig. 3; here the rearsurface stress has been modified using Eq. (1) to represent the in-material response. The good agreement (to within 0.02 GPa) between the front-surface peak constant stress and the adjusted rear-surface data appears to validate the use of Eq. (1). Gauge rise times were $<200 \mathrm{~ns}$; additionally, for clarity, several key features are highlighted on these traces. An initial nonlinear rise followed shock arrival before the stress ramped up to a value known as the Hugoniot stress. The Hugoniot stress was assumed to be the constant value plateau established immediately after shock arrival; however, as shown in Fig. 3, on both gauges a slight ring-up was apparent after c. $40 \%$ of the stress pulse (Hugoniot plateau) duration. However, this step-change in stress was small with a magnitude of c. $0.35 \mathrm{GPa}$ on the front gauge, representing just $4.6 \%$ of the recorded Hugoniot stress. It was also noted that this ring-up was immediately followed by a marked change in the nature of the signal on the rear surface gauge, with large amplitude noise/oscillations occurring. Combined 
TABLE II. Al 5083 H32 plate-impact experimental conditions and results.

\begin{tabular}{|c|c|c|c|c|c|c|c|c|c|}
\hline $\begin{array}{l}\text { Impact velocity } \\
\qquad(\mathrm{m} / \mathrm{s})\end{array}$ & Flyer & Gauges employed & $\begin{array}{l}\text { Rolling direction in } \\
\text { relation to impact axis }\end{array}$ & $\begin{array}{c}\mathrm{u}_{\mathrm{P}} \\
(\mathrm{mm} / \mu \mathrm{s})\end{array}$ & $\begin{array}{c}\mathrm{U}_{\mathrm{S}} \\
(\mathrm{mm} / \mu \mathrm{s})\end{array}$ & $\begin{array}{c}\sigma_{\mathrm{X}} \\
(\mathrm{GPa})\end{array}$ & $\begin{array}{c}\sigma_{\mathrm{Y}} \\
(\mathrm{GPa})\end{array}$ & $\begin{array}{c}\sigma_{\text {spall }} \\
(\mathrm{GPa})\end{array}$ & $\begin{array}{c}\sigma_{\mathrm{HEL}} \\
(\mathrm{GPa})\end{array}$ \\
\hline 195 & $10 \mathrm{~mm}$ Dural & Longitudinal & N/A & 0.094 & 5.43 & 1.54 & $\cdots$ & $\cdots$ & $\cdots$ \\
\hline $200^{\mathrm{a}}$ & $10 \mathrm{~mm}$ Dual & Lateral & N/A & $\cdots$ & $\cdots$ & $1.43^{\mathrm{b}}$ & 1.00 & $\cdots$ & $\cdots$ \\
\hline 206 & $10 \mathrm{~mm}$ Dural & Longitudinal & N/A & 0.098 & 5.67 & 1.54 & $\cdots$ & $\cdots$ & $\cdots$ \\
\hline 309 & $10 \mathrm{~mm} \mathrm{~W}$ & Longitudinal & N/A & 0.261 & 5.45 & 3.41 & $\cdots$ & $\cdots$ & $\cdots$ \\
\hline 361 & 3 mm Dural & Longitudinal & Orthogonal & $\cdots$ & $\cdots$ & $\cdots$ & $\cdots$ & $0.58 \pm 0.03$ & Not visible \\
\hline $410^{\mathrm{a}}$ & $10 \mathrm{~mm} \mathrm{Cu}$ & Lateral & Parallel & $\cdots$ & $\cdots$ & $4.30^{\mathrm{b}}$ & 3.58 & $\cdots$ & $\cdots$ \\
\hline 438 & $10 \mathrm{~mm}$ Dural & Longitudinal /lateral & Orthogonal & 0.213 & 5.86 & 3.32 & 2.44 & $\cdots$ & $\cdots$ \\
\hline 450 & $10 \mathrm{~mm} \mathrm{Cu}$ & Lateral & Orthogonal & $\cdots$ & $\cdots$ & $4.75^{\mathrm{b}}$ & 3.89 & $\cdots$ & $\cdots$ \\
\hline 500 & 5 mm Dural & Longitudinal & Orthogonal & $\cdots$ & $\cdots$ & $\cdots$ & $\cdots$ & $1.30 \pm 0.03$ & $0.59 \pm 0.03$ \\
\hline 506 & 5 mm Dural & Longitudinal & Parallel & $\cdots$ & $\cdots$ & $\cdots$ & $\cdots$ & $1.19 \pm 0.07$ & $0.62 \pm 0.03$ \\
\hline 511 & Dural & Longitudinal & Orthogonal & $\cdots$ & $\cdots$ & $\cdots$ & $\cdots$ & $2.18 \pm 0.08^{c}$ & $058 \pm 0.02$ \\
\hline 657 & $10 \mathrm{~mm} \mathrm{Cu}$ & Lateral & Orthogonal & $\cdots$ & $\cdots$ & $7.57^{\mathrm{d}}$ & 6.27 & $\cdots$ & $\cdots$ \\
\hline 672 & $10 \mathrm{~mm} \mathrm{Cu}$ & Longitudinal & N/A & 0.480 & 5.60 & 7.57 & $\cdots$ & $\cdots$ & $\cdots$ \\
\hline 687 & $10 \mathrm{~mm} \mathrm{Cu}$ & Longitudinal & N/A & 0.485 & 5.87 & 7.68 & $\ldots$ & $\ldots$ & $\ldots$ \\
\hline
\end{tabular}

${ }^{\mathrm{a}}$ Estimate based on previous shots as velocity pin block failed.

${ }^{\mathrm{b}}$ Estimated from the known Al 5083 H32 Hugoniot (Ref. 10).

${ }^{\mathrm{c}}$ Likely a significant overestimate due to gauge misalignment; trace shown in Fig. 6/discussed further in associated text.

${ }^{\mathrm{d}}$ Based on the results of a longitudinal gauge only impact experiment carried out under identical experimental conditions.

with the fact that such a ring-up was not observed on other recorded traces this response was, therefore, tentatively attributed to a gauge response rather than material specific behavior. Finally, a two-stage release is apparent as release waves from the rear of the flyer catch up with the main shock. This two-stage unloading begins elastically before transitioning to plastic unloading. The change in gradient apparent at the elastic-plastic transition is analogous to the HEL (discussed latter) observed on rear-surface gauge traces during the initial rise to the Hugoniot stress. ${ }^{1}$ An interval $\Delta \mathrm{t}_{\text {shock }}$, representing the duration between successive shock arrivals at the front and rear gauges, respectively, is also indicated in Fig. 3. Given a known target thickness this allowed calculation of the shock velocity.

\section{B. Hugoniot relationships}

The $\mathrm{U}_{\mathrm{S}}-\mathrm{u}_{\mathrm{P}}$ Hugoniot relationship for the aluminum alloy considered here, based on the data in Table II, is presented in Fig. 4. Error bars based on earliest and latest reasonable shock arrival times at the two gauges used to

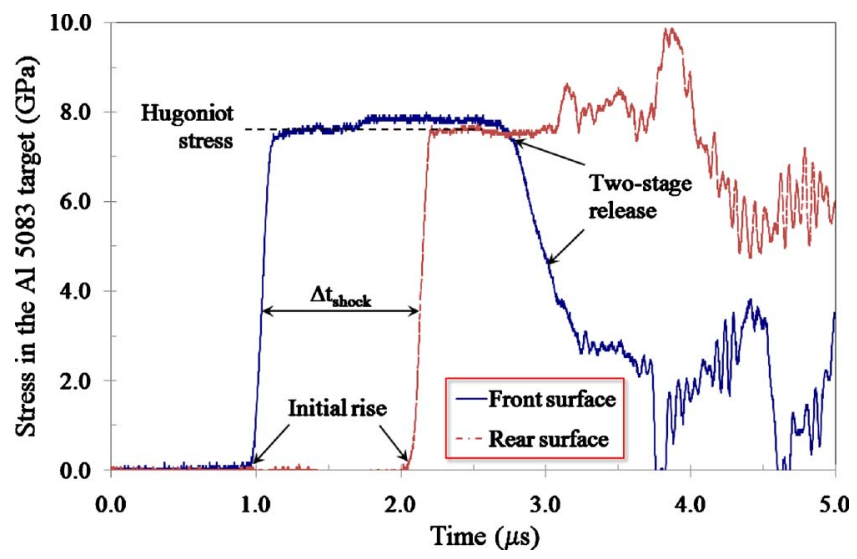

FIG. 3. (Color online) Typical gauge traces; $10 \mathrm{~mm}$ thick $\mathrm{Cu}$ flyer impacting a $6.07 \mathrm{~mm}$ thick Al $5083 \mathrm{H} 32$ target at $672 \mathrm{~m} / \mathrm{s}$. monitor shock passage in these tests (e.g., the potential variability in $\Delta t_{\text {shock }}$ in Fig. 3) have also been included, with errors in $\mathrm{u}_{\mathrm{P}}$ calculated from the measured potential $\mathrm{U}_{\mathrm{S}}$ errors. For the purpose of comparison, best-fits for Al 5083 H131 and $\mathrm{H} 32$, together with original data points for the latter grade, are included based on information from the literature. $^{10}$

Experimental data presented here is in good agreement with the literature data from Boteler and Dandekar ${ }^{10}$ for $\mathrm{Al}$ $5083 \mathrm{H} 32$ - in particular in terms of the measured bulk sound speed. There is, however, a noticeable increase in the magnitude of the error bars for $u_{P} \geq 0.26 \mathrm{~mm} / \mu \mathrm{s}$. This was attributed to the presence of a discernable elastic precursor; at lower particle velocities the associated elastic wave had a sufficient magnitude to noticeably delay the onset of the shock. However, for $u_{\mathrm{P}}>0.26 \mathrm{~mm} / \mu$ s the magnitude of the elastic-plastic wave was sufficient to overtake the elastic precursor. An elastic-only response, with a wave speed equivalent to the elastic wave speed of $6.32 \mathrm{~mm} / \mu$ s set out in Table I, might be expected at particle velocities $<$ that de-

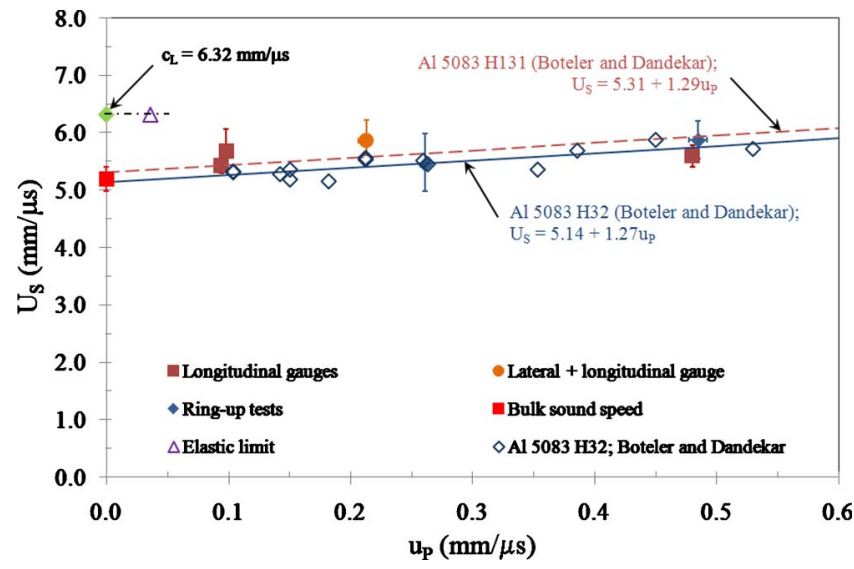

FIG. 4. (Color online) $\mathrm{U}_{\mathrm{S}}-\mathrm{u}_{\mathrm{P}}$ Hugoniot relationship for $\mathrm{Al} 5083 \mathrm{H} 32$; based on Table II plus data presented in the literature (Ref. 10). 


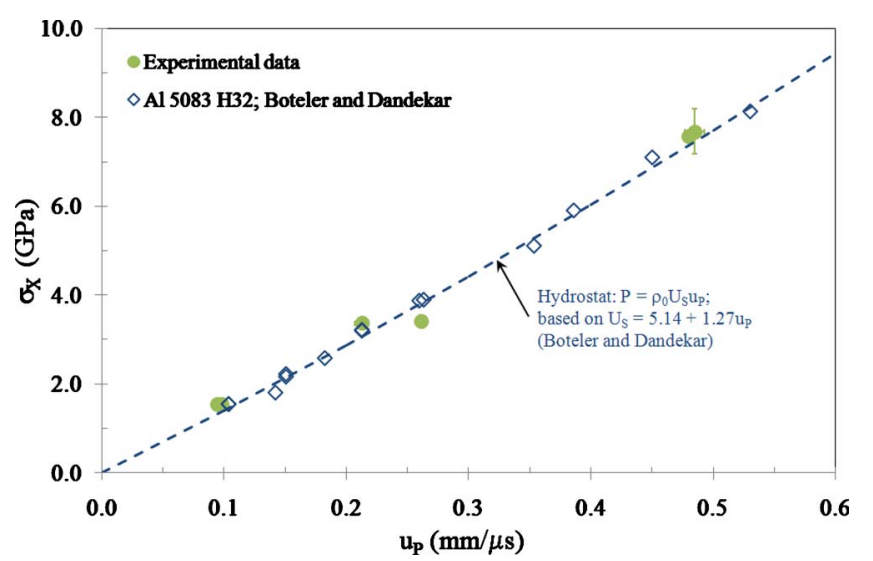

FIG. 5. (Color online) $\sigma_{\mathrm{X}}-\mathrm{u}_{\mathrm{P}}$ relationship for $\mathrm{Al} 5083 \mathrm{H} 32$; data from the literature (Ref. 10) included for comparison.

fined by the HEL. Such a value (e.g., the upper particle velocity at which the HEL will still be readily discernable- $-\mathrm{u}_{\mathrm{HEL}}$ ) may be calculated from Eq. (2). The longitudinal modulus, L, may be calculated from the equation $\mathrm{L}=\rho_{0} \mathrm{c}_{\mathrm{L}} \cdot{ }^{2}$ Therefore, given that $\sigma_{\mathrm{HEL}}$ is the stress at the HEL_an average of $0.605 \mathrm{GPa}$ for Al $5083 \mathrm{H} 32$ from Table II-and using the values for $\mathrm{c}_{\mathrm{L}}$ and $\rho_{0}$ shown in Table I, Eq. (2) gives a particle velocity of $0.036 \mathrm{~mm} / \mu \mathrm{s}$.

$$
u_{\mathrm{HEL}}=\frac{\sigma_{\mathrm{HEL}}}{\sqrt{\rho_{0} \mathrm{~L}}} .
$$

This value is plotted against the Al 5083 longitudinal sound speed (from Table I) in Fig. 4 as the elastic limit (connected to the elastic sound speed $c_{\mathrm{L}}$ by a dashed line). It is immediately apparent that this point lies at a significantly lower particle velocity than all experimental $\mathrm{U}_{\mathrm{S}}-\mathrm{u}_{\mathrm{P}}$ data points, explaining why no elastic-only results were observed.

The $\sigma_{\mathrm{X}}-\mathrm{u}_{\mathrm{P}}$ relationship based on the relevant results presented in Table II is set out in Fig. 5. Experimental data is presented alongside equivalent data for Al 5083 H32 from the literature. ${ }^{10}$ With the experimental data, errors in $\sigma_{\mathrm{X}}$ were based on the range of data over which the Hugoniot stress was established from the constant (Hugoniot) stress plateau, while errors in $u_{P}$ were determined from the variation in $U_{S}$ as previously discussed. There is overall good agreement with the results from Boteler and Dandekar. ${ }^{10}$ As expected, stress increased with impact. However, within both of the data sets considered no evidence of strengthening during loading is apparent. This was indicated by the fact that all data points lie on the Hydrostat, a relationship shown in Fig. 5 which links the particle velocity and observed 1D stress for fluid systems.

\section{Spall strength}

A total of four separate shots utilizing a rear-surface gauge only, protected by c. $1 \mathrm{~mm}$ thick Perspex, were undertaken with the aim of identifying both the HEL $\left(\sigma_{\mathrm{HEL}}\right)$ and spall strength $\left(\sigma_{\text {spall }}\right)$ of the armour-grade aluminum under investigation. While there were indications of an HEL in a number of the standard longitudinal gauge-only shots, the elastic response was more clearly defined in these spall tests

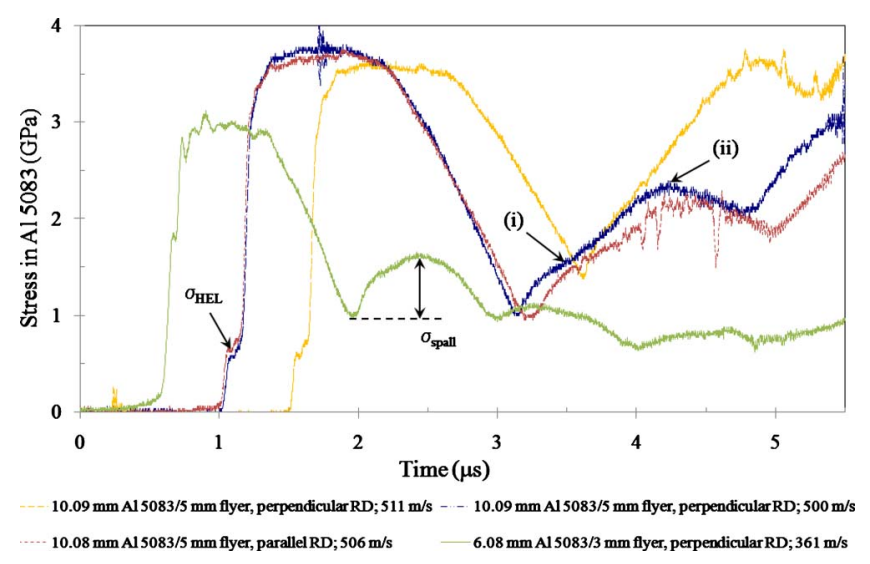

FIG. 6. (Color online) Rear-surface traces following the impact of Dural flyers of varying thickness onto a variety of Al 5083 targets at a range of impact velocities, rescaled according to Eq. (1).

where the thick protective Perspex layer was designed to prevent premature gauge failure. Three shots were undertaken at two different impact stresses using target material with the rolling direction orthogonal to the impact axis to aid identification of any impact stress dependence of $\sigma_{\mathrm{HEL}} / \sigma_{\text {spall }}$, while an additional shot with the rolling direction parallel to the impact axis was used to look for any potential dependence on texture. The gauge traces for these three shots, modified according to Eq. (1) to represent the approximate stress in the target $\mathrm{Al}$, are presented in Fig. 6, with traces spatially separated by up to $0.5 \mu$ s to enhance clarity as appropriate. Typical $\sigma_{\mathrm{HEL}}$ and $\sigma_{\text {spall }}$ (pullback) signals are indicated.

Similar features are apparent on all four traces presented in Fig. 6. In all cases, there is an initial ramped-rise to a gradual peak (the Hugoniot stress). A significant change in gradient, attributed to the elastic limit/HEL, was apparent during the rise for the three c. $500 \mathrm{~m} / \mathrm{s}$ shots. In particular, the good agreement between the 500 and $506 \mathrm{~m} / \mathrm{s}$ traces (which involved targets in which the rolling direction and the impact axis were orthogonal and parallel to each other, respectively) appears to suggest that texture has little effect on either the elastic or spall response of this alloy. The slightly lower amplitude of the Hugoniot stress for the $511 \mathrm{~m} / \mathrm{s}$ shot, despite its higher impact stress, suggests a slight gauge misalignment. While this will have had relatively little effect on early features such as the HEL, later features such as the Hugoniot stress and unloading/reloading (spall pullback) region appear to have been affected as the cumulative effect of gauge misalignment led to a rapid loss of one-dimensionality as the shock propagated through the target. With the $361 \mathrm{~m} / \mathrm{s}$ trace, the data is relatively noisy. This background noise may be attributed to either a poor quality electrical connection to the gauge or slight misalignment. In the first case the increased noise would have effectively swamped the relatively small HEL signal. While the HEL did show up on the misaligned $511 \mathrm{~m} / \mathrm{s}$ shot, in the case of the slower $361 \mathrm{~m} / \mathrm{s}$ shot a slower rise would be expected. Consequently, the HEL would be harder to discern if the gauge were misaligned because the larger resultant rise time would prevent the faster elastic precursor being discerned before it was overtaken in magnitude 
by the main shock. As shown in Fig. 6/Table II, the three c. $500 \mathrm{~m} / \mathrm{s}$ shots give similar values for $\sigma_{\mathrm{HEL}}$ - with an average of $0.60 \pm 0.02 \mathrm{GPa}$. It is interesting to note that this is significantly higher than the value of $0.40 \pm 0.03 \mathrm{GPa}$ found elsewhere for Al $5083 \mathrm{H} 32 .{ }^{10}$ However, it is in good agreement with the average value of $0.57 \pm 0.04 \mathrm{GPa}$ for H131. Direct comparison between results is difficult, however, as different calibration approaches were employed. Boteler and Dandekar ${ }^{10}$ used transmission experiments combined with both VISAR systems and quartz gauges to measure spall strengths for the H32 and H131; whereas, here transmission experiments combined with manganin stress gauges were employed.

Following release spall pullback signals consisting of a dip in stress followed by an increase in stress/reloading are apparent in all traces. In each case, two distinct steps may be discerned during the subsequent reloading, labeled as (i) and (ii) on the c. $500 \mathrm{~m} / \mathrm{s}$ shots in Fig. 6. A similar response was observed for $\mathrm{Al} 7017$ by Millett et al., ${ }^{5}$ although no explanation is given. As a spall pullback response involves reloading of material, it seems reasonable to suggest that the observed two-stage rise is analogous to an elastic-plastic loading. In this situation the change in gradient during the reloading would represent the transition from elastic to plastic behavior. This raises the question of which feature (elastic or plastic) should be used to measure magnitude of the pullback signal. Here, in line with Millett et al., ${ }^{5}$ the spall response is assumed to be the total reloading signal-e.g. $\sigma_{\text {spall }}$ in Fig. 6. As outlined above, there is significant evidence of misalignment with the $511 \mathrm{~m} / \mathrm{s}$ shot, namely a relatively low Hugoniot stress compared to the otherwise identical slightly lower impact velocity c. $500 \mathrm{~m} / \mathrm{s}$ shots. The significantly greater magnitude of the spall pullback signal on the $511 \mathrm{~m} / \mathrm{s}$ shot when compared to the other two c. $500 \mathrm{~m} / \mathrm{s}$ shots is consequently attributed to the loss of one-dimensionality at the rear-surface gauge. Consequently, the spall strength from this shot is not considered here. Similar spall strengths were measured on the 500 and $506 \mathrm{~m} / \mathrm{s}$ shots; while the value for the sample with the rolling direction orthogonal to the impact axis $(500 \mathrm{~m} / \mathrm{s})$ was larger at $1.30 \pm 0.03 \mathrm{~m} / \mathrm{s}$, the value for the sample with the rolling direction parallel to the impact axis was only just outside the associated error bounds at $1.19 \pm 0.07 \mathrm{~m} / \mathrm{s}$. Consequently, particularly given the good agreement between the traces for these two shots in Fig. 6, it seems reasonable to take these values as being approximately equal. As such, the average value of $\sigma_{\text {spall }}$ at an impact pressure of c.3.7 $\mathrm{GPa}$ is taken as $1.23 \pm 0.05 \mathrm{GPa}$. As far as the authors are aware no similar information for $\mathrm{Al}$ $5083 \mathrm{H} 32$ is currently present in the open literature; the nearest comparison being a value of $0.936 \pm 0.005 \mathrm{GPa}$ found by Boteler and Dandekar ${ }^{12}$ for H131, approximately $24 \%$ lower than the value measure for the similar grade of $\mathrm{Al}$ here. This is somewhat surprising as H131 is strain-hardened only, whereas, $\mathrm{H} 32$ is also partially annealed ${ }^{10}$ but may again be attributable to differences in experimental technique or even variability in properties across as-rolled source material. Spall strengths were measured at impact stresses in the range $1.6-7.8 \mathrm{GPa},{ }^{10,12}$ with no stress-dependence found. The pure O-temper was also noted to show a spall strength of c.1.6
$\mathrm{GPa},{ }^{12}$ significantly above that of either H131 (Ref. 12) or H32 (measured here). It is interesting to note that a significantly lower spall strength of $0.58 \pm 0.03 \mathrm{GPa}$ was apparent from the $361 \mathrm{~m} / \mathrm{s}$ trace in Fig. 6 . There is tentative evidence in the literature of an impact stress dependence for $\sigma_{\text {spall }}$ in Al 7010 in the T6 temper, ${ }^{6}$ where the spall strength was found to increase with impact stress when the impact axis was aligned with the rolling direction and decrease when orthogonal to the impact axis. However, in this case the opposite relationship between spall strength and rolling direction would apply. Further, there are a number of issues which would initially seem to prevent such a conclusion being reached here: (1) the similarity in $\sigma_{\text {spall }}$ independent of texture apparent in Fig. 6 for the 500/506 m/s shots; (2) the lack of strain-rate dependence noted in the similar alloy Al 5083 $\mathrm{H} 131,{ }^{12}$ and; (3) the aforementioned lack of an HEL on the $361 \mathrm{~m} / \mathrm{s}$ trace, potentially indicating a degree of misalignment. Conversely, when the Al $5083 \mathrm{H} 32$ Hugoniot from the literature ${ }^{10}$ is used to predict a theoretical longitudinal stress for the shot conditions set out in Table II for the $361 \mathrm{~m} / \mathrm{s}$ shot, a value of $\sigma_{\mathrm{X}}=\mathrm{c} .2 .7 \mathrm{GPa}$ is predicted. This compares well with the recorded value of c.2.9 GPa from Fig. 6, particularly given the use of Eq. (1) to convert the measured rear-surface stress to this value. If significant misalignment were present a lower stress would be expected. As such, the $361 \mathrm{~m} / \mathrm{s}$ shot does appear to show tentative evidence of a positive relationship between spall strength and impact stress when the rolling axis is orthogonal to the impact axis in this aluminum. However, due to the issues highlighted above, and in particular the previously observed lack of such a dependence in the similar grade H131, further work will be required before any firmer conclusions may be reached. Material was recovered post-impact for three of the four spall strength tests detailed in Table II/Fig. 6; namely the 361, 500, and $506 \mathrm{~m} / \mathrm{s}$ shots. In addition, material was also recovered from an additional spall shot not listed in Table II due to a problem with the attached oscilloscope which prevented data recording. The sample, impacted by a Dural flyer at $517 \mathrm{~m} / \mathrm{s}$, and which possessed a rolling direction parallel to the impact axis, was recovered for further analysis. While subject to the effects of releases from both the rear of the flyer and sample edges post-impact, it was nonetheless felt that such recovered material, combined with stress histories where captured, might be sufficient to provide a qualitative insight into the evolution of spall features within the armour-grade of aluminum under consideration. Such analysis has been conducted elsewhere on Al 7017 (Ref. 5) with useful results and, therefore, seems a reasonable approach here. Through-thickness sections were taken and polished/etched (with Kellers reagent ${ }^{21}$ ) to highlight the resultant spall planes. Typical resultant micrographs for each case, with experimental configuration and microstructural orientation noted are shown in Fig. 7. In each case the impact axis is toward the top/bottom of the page.

Definite spall planes (indicated by white arrows) were apparent in all samples considered, which, in all but the 361 $\mathrm{m} / \mathrm{s}$ case, were fully interconnected. At $361 \mathrm{~m} / \mathrm{s}$ - e.g., Fig. $7(a)$, the spall plane was relatively diffuse and significantly harder to detect then in the three c. $500 \mathrm{~m} / \mathrm{s}$ shots. Secondary 


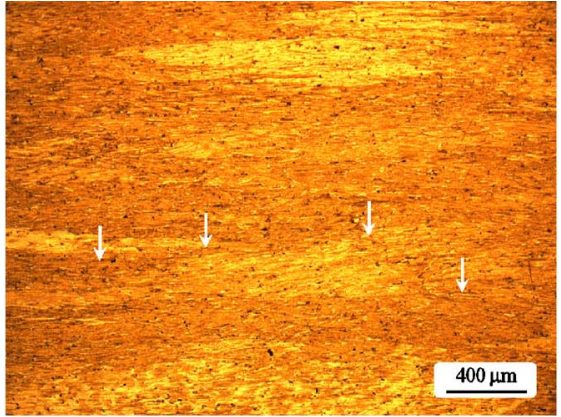

(a) $3 \mathrm{~mm}$ Dural flyer @ $361 \mathrm{~m} / \mathrm{s}$; RD orthogonal to impact axis; $\sigma_{\text {spall }}=0.58 \pm 0.03 \mathrm{GPa}$

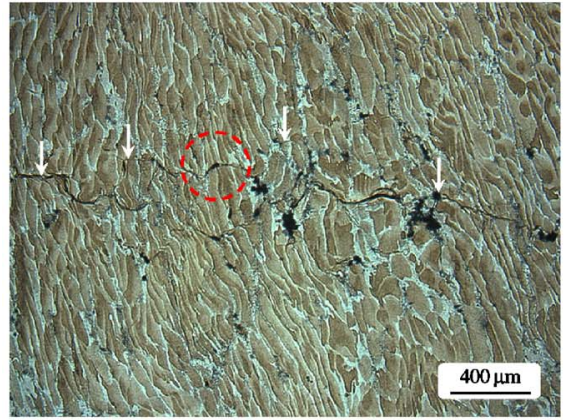

(c) $5 \mathrm{~mm}$ Dural flyer @ $506 \mathrm{~m} / \mathrm{s}$; RD parallel to impact axis;

$\sigma_{\text {spall }}=1.19 \pm 0.07 \mathrm{GPa}$

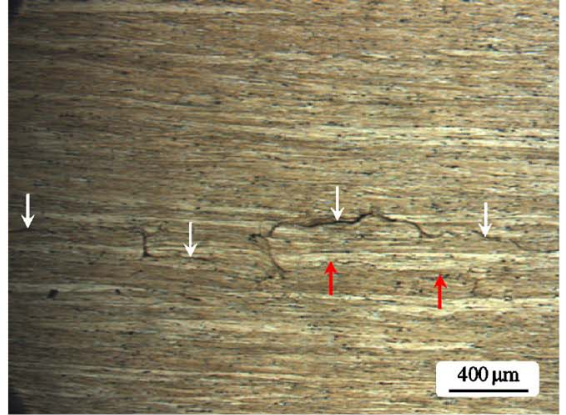

(b) $5 \mathrm{~mm}$ Dural flyer @ $500 \mathrm{~m} / \mathrm{s}$; RD orthogonal to impact axis; $\sigma_{\text {spall }}=1.30 \pm 0.03 \mathrm{GPa}$

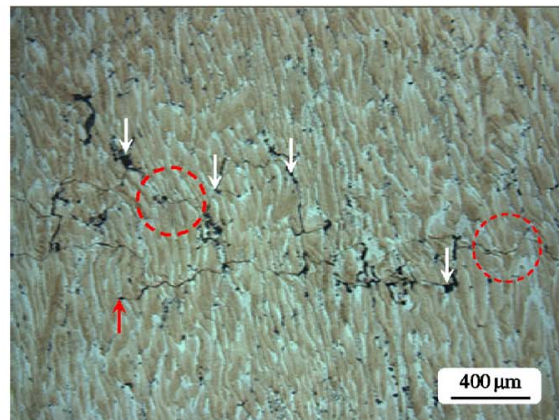

(d) $5 \mathrm{~mm}$ Dural flyer @ $517 \mathrm{~m} / \mathrm{s}$; RD parallel to impact axis;

$\sigma_{\text {spall }}$ not recorded
FIG. 7. (Color online) Optical micrographs illustrating spall planes in a selection of recovered aluminum targets; white arrows highlighting spall planes, red arrows secondary spall planes and red dashed circles illustrating transgranular fracture. spall planes, demonstrating a more complex threedimensional structure and finite thickness to the interaction region, were also apparent in Figs. 7(b)-7(d); highlighted by darker (red) arrows in Fig. 7(b) only for clarity. All micrographs showed evidence of inclusions (small black points in-between other structures), likely $\mathrm{Mn} / \mathrm{Mg}$-rich intermetallic phases. $^{5,10}$ In both Figs. 7(a) and 7(b), where the rolling direction was set orthogonal to the impact axis, individual grains proved difficult to discern; instead the general texture along the rolling direction (along the width of the page in these two micrographs) was the dominant feature. Spall appeared to follow the diffuse elongated grain boundaries and, while there was tentative evidence of initiation at intermetallic particles/grain boundaries, the diffuse nature of the grains made analysis difficult. The situation in Figs. 7(c) and 7(d) was much clearer. Here, the rolling direction ran parallel to the impact axis (down the length of the page in this case). Despite an identical preparation process to the samples with the rolling direction orthogonal to the impact axis, individual grains were much more clearly defined. Spall planes (both primary and secondary) were seen to propagate between inclusions. In Fig. 7(d) one particular element of the spall plane (highlighted by a red arrow) is observed to start or stop at an inclusion. This clearly links the inclusions to either the point of initiation or termination of the spall planes, confirming that spall occurred between such regions. This ties in well with a similar analysis of spall initiation in $\mathrm{Al} 7017$ conducted by Millett et al. ${ }^{5}$ where optical micrographs of recovered spall samples showed incomplete spall planes initiating around $(\mathrm{Fe}, \mathrm{Mn}) \mathrm{Al}_{6}$ inclusions. It is also interesting to note that while many of the elements of the spall planes appear to propagate around grain boundaries, unlike the orthogonal rolling axis case in Figs. 7(a) and 7(b), a significant number of transgranular fractures occur (examples are highlighted by dashed circles in both micrographs). It is notable that similar spall strength magnitudes and pullback signals are apparent for the $500 \mathrm{~m} / \mathrm{s}$ and $506 \mathrm{~m} / \mathrm{s}$ shots in Fig. 6 despite the substantial difference in fracture architecture apparent in Figs. 7(b) and 7(c), respectively. Given the greater strength of individual grains as opposed to grain boundaries, this result appears to suggest that the tensile spall strength is significantly higher than the transgranular fracture stress. Consequently, once reached the spall strength is independent of the texture/granular orientation and associated fracture mode.

\section{Lateral stress behavior}

A number of experiments, some of which have been previously reported, ${ }^{13}$ were carried out to determine the lateral stress behavior of the armour-grade aluminum under investigation both on shock arrival and behind the shock front. Lateral gauges were embedded $2 \mathrm{~mm}$ from the impact face in each case. All but one of the experiments were undertaken with the Al short-transverse direction parallel to the impact axis (e.g., with the rolling direction orthogonal to the target surface). The additional experiment was, for the purpose of comparison, undertaken with the rolling direction parallel to the impact axis. Experimental conditions for these shots are included in Table II, along with the source for the associated Hugoniot stress value (either a longitudinal gauge-only experiment under identical conditions, a rear-surface longitudi- 


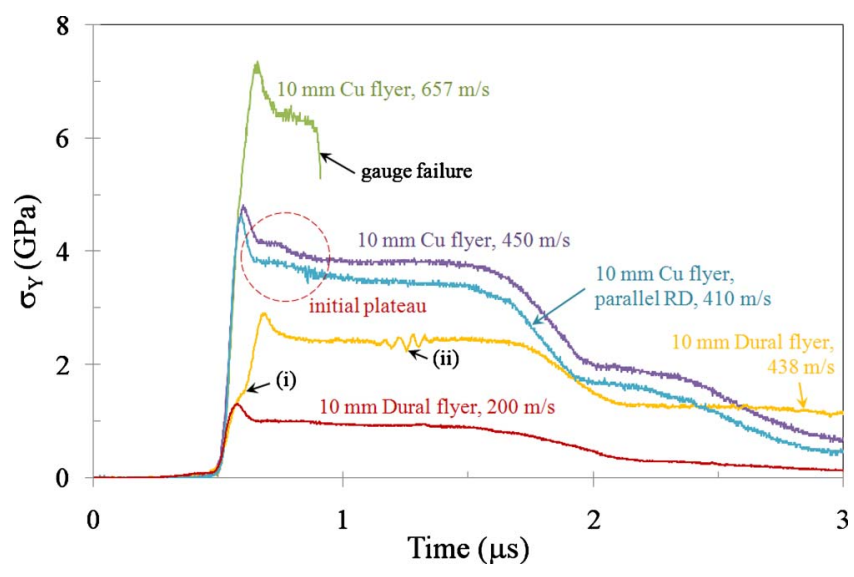

FIG. 8. (Color online) Recorded lateral gauge traces for the shots incorporating lateral gauges detailed in Table II.

nal gauge or an estimate from the known $\mathrm{Al} 5083 \mathrm{H} 32$ Hugoniot relationship ${ }^{10}$ ). The recorded lateral gauge traces are presented in Fig. 8; they comprise four traces previously presented by Appleby-Thomas et al. ${ }^{13}$ together with a new trace from an impact experiment at $410 \mathrm{~m} / \mathrm{s}$ onto a target whose rolling direction was parallel with the impact axis. In order to allow direct comparison no modification/smoothing of the experimental data has been undertaken, beyond calibration to calculate record lateral stress magnitudes and resetting of the shock arrival times to a nominal $0.5 \mu$ s to facilitate comparison.

All of the recorded lateral gauge traces shown in Fig. 8 exhibited a number of similar features. An initial ramp was present in each case-as this had a gradient independent of impact stress this phenomenon was assumed to be a gauge response. Following the initial ramp a rise to a peak stress occurred with a typically duration of $<180 \mathrm{~ns}$. This relatively slow rise time is a function of the lateral gauge response and has been observed elsewhere. ${ }^{15}$ The peak stress was observed to represent an overshoot of c.100 ns duration in each case before a lateral stress plateau was established. Such behavior has been observed elsewhere in the lateral stress response of $\mathrm{Ni}$ (also fcc like $\mathrm{Al}$ ), where this short duration was taken to imply a link between the overshoot and establishment of gauge equilibrium rather than a material response. ${ }^{4}$ A lateral stress plateau followed the initial gauge overshoot in each case before the experiment was terminated by arrival of release waves from the rear edge of the impacting flyer leading to a two-stage elastic/elastic-plastic release. A very slight gradient was apparent in the lateral stress plateau for a number of these traces, although not in the $438 \mathrm{~m} / \mathrm{s}$ case. However, where a gradient occurred it tended to be most pronounced following a small initial plateau, with an essentially constant stress resulting thereafter. This initial plateau following the rise to the peak stress was most pronounced in the higher stress impacts. This feature was predominately observed on impacts involving $\mathrm{Cu}$ flyers (e.g., the 410, 450 and, likely, although partially obscured by premature gauge failure, $657 \mathrm{~m} / \mathrm{s}$ shots). However, as shown in Fig. 9, at a higher resolution a plateau was also apparent on the $200 \mathrm{~m} / \mathrm{s}$ shot which involved a Dural flyer impacting the Al 5083 target. For the $200 \mathrm{~m} / \mathrm{s}$ shot (Fig. 9), the lateral

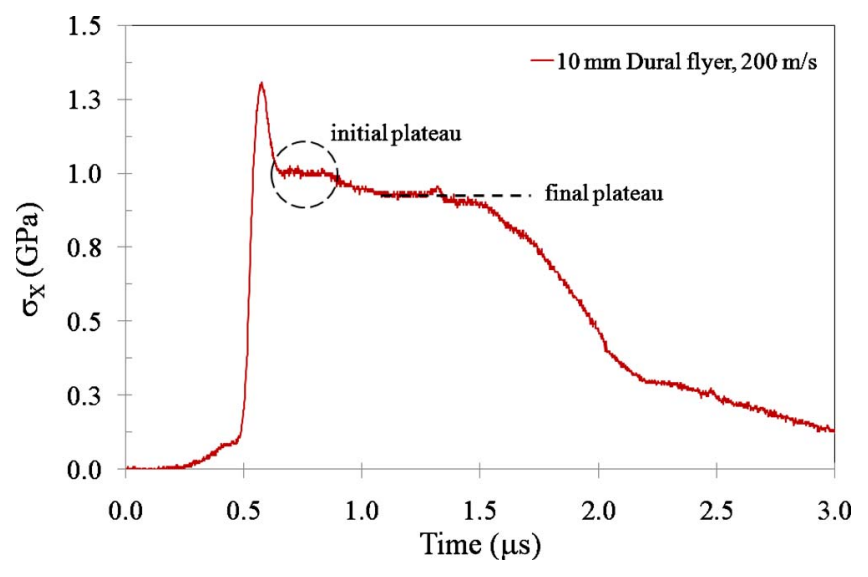

FIG. 9. (Color online) Higher resolution version of the $200 \mathrm{~m} / \mathrm{s}$ lateral gauge trace shown in Fig. 8.

stress region following the initial overshoot consisted of an initial plateau of c.200 ns duration followed by a decrease in stress over c. $170 \mathrm{~ns}$ to a final essentially constant plateau which lasted c. 370 ns before releases from the rear of the flyer arrived to end the shock. The duration of the initial plateau and subsequent gradient was of a similar order-ofmagnitude for the higher impact shots shown in Fig. 8; e.g., in the $450 \mathrm{~m} / \mathrm{s}$ case the initial plateau/subsequent gradient had durations of 70/200 ns, respectively. Gradients in lateral stress have been shown elsewhere to imply a change in shear strength behind the shock. Maximum shear strength $(\tau)$ is related to the associated longitudinal and lateral/transverse stresses by Eq. (3). Due to inertial confinement the longitudinal stress measured during a 1D plate-impact experiment should be approximately constant for the duration of the shock pulse. The relatively constant magnitude of the Hugoniot stresses in Fig. 3 shows that this is indeed the case here. Consequently, from Eq. (3), any variation in $\sigma_{\mathrm{Y}}$ behind the shock can be interpreted as a variation in shear strength.

$$
\tau=\frac{\sigma_{\mathrm{X}}-\sigma_{\mathrm{Y}}}{2} .
$$

A similar lateral response to that observed here was noted by Millett et al. ${ }^{4}$ in the lateral response of $\mathrm{Ni}$; comprising an initial plateau with a negative gradient leading to a constant stress. Millett et al. ${ }^{4}$ found the duration of the plateau/ gradient region to be c.800 ns and the effect was linked to a material response representing - from Eq. (3) - hardening behind the shock. In particular, it was postulated that the high stacking fault energy of Ni led to rapid dislocation generation during compression and, consequently, a reduction in the ability of the material to produce further dislocations postshock (e.g., hardening). In this case, however, the observed plateaus and subsequent gradients in lateral stress had significantly shorter durations than those observed by Millett et al., ${ }^{4}$ with a maximum total duration of c.370 ns exhibited in the $200 \mathrm{~m} / \mathrm{s}$ case. Further, in these tests lateral gauges were placed just $2 \mathrm{~mm}$ from the impact face, whereas Millett et al. placed gauges at a depth of $4 \mathrm{~mm}$. This relatively short duration of the initial plateau/gradient combined with the fact that at a position of $2 \mathrm{~mm}$ from the impact face small perturbations in the gauge response may not have had time to 
fully damp-out, suggests a gauge response. This concept that the initial plateau-based feature represents a gauge rather than material response is further reinforced by the lack of a discernable plateau on the $438 \mathrm{~m} / \mathrm{s}$ shot in Fig. 8; the relatively lazy rise time on this gauge appears to have smoothedout any initial effects. With regards to the interpretation of gradients behind the shock in lateral gauges it should also be noted that recent work by Winter and Harris ${ }^{22}$ and Winter et $a l{ }^{23}$ has suggested a modification to the approach adopted by others. $^{4,13,15,24,25}$ Winter and Harris ${ }^{22}$ and Winter et al. ${ }^{23}$ employed a combination of simulation and experiment to investigate the propagation of shocks through both a so-called matrix material and a matrix material with an embedded fluid layer (analogous to an encapsulated gauge). They showed that the presence of a fluid layer leads to significant modifications of the nature of the shock front, modifying the gradient of the resultant lateral gauge trace behind the shock. A faster shock in the fluid layer was shown to produce a positive gradient in lateral stress. Conversely, a slower shock front in this region was observed to lead to an initial ramp to a peak followed by a steady decrease in lateral stress magnitude (a response linked to the formation of a Mach stem in the fluid layer). Interestingly, recent work by Brown and Ravichandran $^{26}$ focused on shock behavior in convergent geometries appears to back the concept of shock dispersion in an interlayer. ${ }^{22,23}$ Simulations of shock propagation in a configuration known as a Mach lens comprising a $\varnothing 4 \mathrm{~mm}$ PMMA cylinder contained within a concentric $\varnothing 34 \mathrm{~mm} \mathrm{Al}$ cylinder showed that formation of a Mach stem results in the lower shock velocity PMMA. It should be noted that the length scale of the PMMA cylinder was very much larger than the typical lateral encapsulation length scale of c. $100 \mu \mathrm{m}$. Despite this, the results presented by Brown and Ravichandran ${ }^{26}$ do hint at the possibility of shock dispersion in a target incorporating an encapsulated lateral gauge. While a significant body of work suggesting that lateral gauges do record material phenomena behind the shock exists in the literature, ${ }^{4,13,15,24,25}$ it is clear from Winter and Harris ${ }^{22}$ and Winter et al. ${ }^{23}$ that substantial doubt as to the validity of this approach remains. Therefore, in relation to inference of any strengthening effects it is clear that care should be taken in lateral gauge interpretation. However, given the relatively flat gradient behind the shock apparent in all cases in Fig. 8 and, assuming the observed initial plateau/gradient are gauge phenomena, it seems reasonable to conclude that that little change in lateral stress with time occurs under shock loading for the armour-grade aluminum under investigation.

Another feature of interest in Fig. 8 was a slight kink observed at point (i) in the $438 \mathrm{~m} / \mathrm{s}$ rise. This appeared to have a similar frequency to the subsequent overshoot and was, therefore, previously tentatively attributed to ringing within the gauge package by Appleby-Thomas et al. ${ }^{13}$ However, further observation showed that the initial gradient up to this kink was equivalent to that of the $200 \mathrm{~m} / \mathrm{s}$ shot, with the kink leading to a gradient closer to that seen in the higher velocity impacts. Given this similarity of response it is interesting to note that the 200 and $438 \mathrm{~m} / \mathrm{s}$ shots were the only ones involving a Dural flyer; however, insufficient information was available to confirm any physical phenomena re-

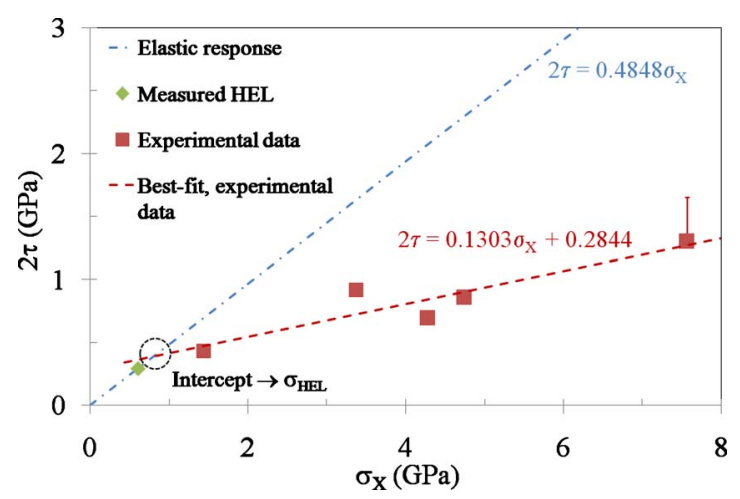

FIG. 10. (Color online) Variation in shear strength with impact stress for an armour-grade aluminum, based on the data presented in Table II/Fig. 8.

sponsible for this kink in the $438 \mathrm{~m} / \mathrm{s}$ trace. Finally, noise at point (ii) in the $438 \mathrm{~m} / \mathrm{s}$ shot in Fig. 8 was correlated with shock arrival at the attached rear-surface gauge. It is also worth noting the good correlation in terms of the shape of the recorded trace between the 410 and $450 \mathrm{~m} / \mathrm{s}$ shots, with the $410 \mathrm{~m} / \mathrm{s}$ shot almost exactly mirroring the slightly higher pressure trace all the way through to the arrival of the release from the rear of the flyer plate which ends the experiment. The only difference-apart from impact velocity-between these experiments was that in the former case the target $\mathrm{Al}$ rolling direction was parallel to the axis of impact and in the latter it was orthogonal. Therefore, this good agreement is taken as a strong indication that grain orientation has no discernable effect on transverse stress evolution under 1D impact.

As discussed, despite some recent questions about the interpretation of lateral gauge traces, ${ }^{22,23}$ this approach of using embedded lateral gauges to monitor changes in shear strength behind the shock has been employed extensively in the literature. 4,13,15,25 However here, if the initial gradient in lateral stress apparent at elevated impact phenomena is indeed linked to the experimental apparatus employed rather than a material response, the flat nature of the final lateral stress plateaus illustrated in Fig. 8/the data presented in Table II suggests that strengthening behind the shock does not occur in this armour-grade aluminum at longitudinal impact stresses $\leq 7.57 \mathrm{GPa}$ (e.g., the $657 \mathrm{~m} / \mathrm{s}$ shot). As such, only the absolute magnitude of the shear strength at each impact stress will be considered here. Using data from Table II and assuming that Hugoniot stresses are constant, Fig. 10 shows the variation in shear strength with (either calculated or recorded) impact stress based on Eq. (3) for the five lateral gauge-based experiments undertaken. These results are somewhat different to those presented for four of the data points previously ${ }^{13}$ due to a reinterpretation of the data presented in Fig. 8 in light of more detailed analysis of the structure of individual gauge traces. The premature failure of the lateral gauge in the $657 \mathrm{~m} / \mathrm{s}$ shot in Fig. 8, combined with the variation across the lateral stress for the other shot records made the choice of sampling position for $\sigma_{\mathrm{Y}}$ problematic. For consistency, the decision was taken to sample data immediately below the dip following the initial plateau where present; in the case of the $657 \mathrm{~m} / \mathrm{s}$ shot the sampling point, therefore, comprised the lowest recorded lateral stress 
before gauge failure. Nevertheless, this approach has led to an increase in the uncertainty on this measured data point. To try and quantify this error an assessment of the magnitude of the drop in stress between the initial and final plateaus for all of the traces shown in Fig. 8 was undertaken. The position of these plateaus was chosen in each case (except the $657 \mathrm{~m} / \mathrm{s}$ shot due to the premature gauge failure) to correspond with those illustrated on the high-resolution version of the 200 $\mathrm{m} / \mathrm{s}$ trace shown in Fig. 9. Declines in lateral stress of between $0.07 \mathrm{GPa}$ at an impact velocity of $200 \mathrm{~m} / \mathrm{s}$ and 0.33 $\mathrm{GPa}$ at $450 \mathrm{~m} / \mathrm{s}$ were noted. Consequently, a decrease in $\sigma_{\mathrm{Y}}$ of at least $0.33 \mathrm{GPa}$ would be expected for the $657 \mathrm{~m} / \mathrm{s}$ shot if gauge failure had not occurred; corresponding from Eq. (3) to a similar increase in $2 \tau$. To this end, while errors on the other data points were consistently relatively small and have, therefore, been omitted for clarity, an error of $+0.35 \mathrm{GPa}$ on the $2 \tau$ value for the $657 \mathrm{~m} / \mathrm{s}$ shot has been introduced. Further, a predicted elastic response based on Eq. (4), with $\nu$ $=0.34$ taken from Table $\mathrm{I}$, is also included for comparison. $^{4,15,25}$ In addition, a data point representing the average measured $\sigma_{\mathrm{HEL}}$ value of $0.60 \mathrm{GPa}$ has also been included in Fig. 10.

$$
2 \tau=\frac{1-2 \nu}{1-\nu} \sigma_{\mathrm{X}}
$$

A clear linear relationship between shear strength and impact stress is apparent in Fig. 10. As deviation from the elastic response represents the onset of plastic deformation, the intercept of the experimental data with the elastic response should represent the elastic limit-e.g. $\sigma_{\mathrm{HEL}}$. This intercept, indicated in Fig. 10, corresponds to a value of $\sigma_{\mathrm{HEL}}$ $=0.80 \mathrm{GPa}$, approximately a third higher than the average measured value of $0.60 \mathrm{GPa}$. However, as discussed the highest magnitude shear strength data point, corresponding to the $657 \mathrm{~m} / \mathrm{s}$ trace in Fig. 8, has a large potential error due to premature gauge failure. If the maximum extent of this potential error where realized the corresponding best fit to the experimental data would be $2 \tau=0.1847 \sigma_{\mathrm{X}}+0.1178$, giving an intercept $/ \sigma_{\mathrm{HEL}}$ of $0.40 \mathrm{GPa}$. Interestingly, this value is closer to that for Al $5083 \mathrm{H} 32$ presented in the literature ${ }^{10,13}$ of c. $0.45 \mathrm{GPa}$. Consequently, this approach suggests that the HEL for the armour-grade aluminum considered here is likely to lie between the two extremes of 0.40 and $0.80 \mathrm{GPa}$. Nonetheless, given the differences in approach (e.g., the use of different gauge types/techniques) between this work and that of Boteler and Dandekar ${ }^{10}$ and the fact that potential errors on shear strength data presented in Fig. 10 have not been considered for any point except the $657 \mathrm{~m} / \mathrm{s}$ shot data, the agreement between the average HEL value of $0.60 \pm 0.02 \mathrm{GPa}$ measured here and that for Al $5083 \mathrm{H} 32$ presented elsewhere ${ }^{10}$ is arguably sufficient to confirm the $\mathrm{Al}$ 5083 H32 HEL order-of-magnitude.

\section{CONCLUSIONS}

The evolution of lateral stress in an armour-grade aluminum alloy has been studied using 1D plate-impact experiments at impact velocities in the range 195-687 m/s, equivalent to the pressure regime 1-8 GPa. Hugoniots have been established in the $\mathrm{U}_{\mathrm{S}}-\mathrm{u}_{\mathrm{P}}$ and $\mathrm{P}-\mathrm{u}_{\mathrm{P}}$ planes using embedded longitudinal manganin stress gauges and were found to be in good agreement with literature data for Al 5083 (H32). A linear relationship in the $\mathrm{U}_{\mathrm{S}}-\mathrm{u}_{\mathrm{P}}$ plane was confirmed, while agreement with calculated hydrostatic behavior at longitudinal impact stresses up to $7.68 \mathrm{GPa}$ suggested that no enhanced strengthening with increased impact stress occurred. Rear-surface mounted longitudinal stress gauges were used to investigate changes in both the HEL and spall strength with impact stress and grain orientation of the target aluminum. The HEL was found to be constant under all conditions with an average measured value of $0.60 \pm 0.02 \mathrm{GPa}$. While shown to be independent of grain orientation, there were tentative indications that spall strength may increase with impact stress. However, insufficient information was found to confirm this effect and instead a value of $1.23 \pm 0.05 \mathrm{GPa}$ at an impact stress of c.3.7 GPa was recorded, with further work planned to investigate this behavior more fully. Microstructural analysis of recovered spall targets was undertaken using an optical microscope. This enabled identification of the spall planes within the target material. Rather than having a discrete location the spall planes were shown to have a finite three-dimensional extent within the target material. Evidence, in the form of a site of either termination or initiation of spall, was found to suggest that spall planes propagated between inclusions within the target aluminum. In addition, it was shown that the fracture phenomena depended on grain orientation. When the elongated rolling direction was aligned with the impact axis the formation of the perpendicular spall plane led to transgranular failure, compared to a predominantly grain-boundary based failure mode with an orthogonal rolling direction. Despite this difference in failure-modes, as outlined above, no relationship between spall strength and microstructural orientation was found. This was taken to imply that the tensile spall strength was significantly higher than the transgranular fracture strength.

The evolution of lateral stress with impact stress was also investigated using embedded lateral manganin stress gauges. In good agreement with the $\mathrm{P}-\mathrm{u}_{\mathrm{P}}$ behavior, no evidence of a change in gradient-and, therefore, change in strength-behind the shock was apparent. In line with analysis of Al 6082-T6 reported in the literature, this is likely due to the presence of dispersed intermetallic particles acting to prevent the formation of ordered dislocation cells. However, an unusual three-stage phenomenon was encountered in the lateral stress plateaus. Following shock arrival an initial plateau was encountered in most cases followed by a decrease to a significantly longer-duration constant plateau. While similar phenomena elsewhere have been attributed to hardening behind the shock, here the initial two stages were shown to occur over durations of c.400 ns, considered too short for a material response. Instead, these phenomena were attributed to a gauge response enhanced by placement of the embedded lateral gauges just $2 \mathrm{~mm}$ from the impact face of manufactured targets. Lateral stress results were combined with the known material Hugoniot to calculate the change in shear strength with impact stress, which as-expected was found to be linear in nature. By comparison to the isotropic elastic prediction an estimate of the HEL was made based on 
this data. Due to experimental errors a value in the range 0.4-0.8 GPa was suggested, bracketing the value of $0.60 \pm 0.02 \mathrm{GPa}$ measured independently using rear-surface longitudinal stress gauges.

Overall, this study has looked at the dynamic properties of the armour-grade aluminum 5083 in the H32 temper; focusing in particular on the strength of the alloy under shock loading. Little evidence of strengthening either under increased load or behind the shock was apparent. Spall strength was found to be higher than that for the similar grade of Al $5083 \mathrm{H} 131$, although elastic properties were comparable. This later point was in contrast to earlier work on H32; however, given the similarity between these two alloys (with the only difference being that H131 was strainhardened only and H32 strain-hardened/partially annealed), it is difficult to distinguish their properties - as evidenced by the similar Hugoniot relationships available in the literature/ reproduced in this paper. Further, spall was shown to initiate at the site of intermetallic inclusions within the worked aluminum. Finally, unlike Al 7010 in the T6 temper, no dependence of behavior under shock with grain orientation was found.

\section{ACKNOWLEDGMENTS}

The authors wish to acknowledge the support of the Institute of Shock Physics based at Imperial College London (funded via The UK Ministry of Defense). We are also grateful for the technical support provided by Mr. Andy Roberts, for invaluable aid with the experimental work associated with this paper and Mr. Adrian Mustey for preparation of metallographic samples. In addition, we would like to thank Dr. J. C. F. Millett for valuable discussions. British Crown Copyright MOD/2010.

${ }^{1}$ M. A. Meyers, Dynamic Behavior of Materials (Wiley, New York, 1994). ${ }^{2}$ H. Huang and J. R. Asay, J. Appl. Phys. 98, 033524 (2005).

${ }^{3}$ W. D. Callister, Jr., Materials Science and Engineering: An Introduction (Wiley, New York, 2003).
${ }^{4}$ J. C. F. Millett, G. Whiteman, and N. K. Bourne, J. Appl. Phys. 105, 033515 (2009).

${ }^{5}$ J. C. F. Millett, N. K. Bourne, and M. R. Edwards, Scr. Mater. 51, 967 (2004).

${ }^{6}$ M. R. Edwards, N. K. Bourne, and J. C. F. Millett, in Shock Compression of Condensed Matter, edited by M. D. Furnish, N. N. Thadhani, and Y. Horie (AIP, New York, 2001), pp. 523-526.

${ }^{7}$ A. H. Clausen, T. Børvik, O. S. Hopperstad, and A. Benallal, Mater. Sci. Eng., A 364, 260 (2004).

${ }^{8}$ F. Grytten, T. Børvik, O. S. Hopperstad, and M. Langseth, Int. J. Impact Eng. 36, 597 (2009).

${ }^{9}$ T. Børvik, A. H. Clausen, O. S. Hopperstad, and M. Langseth, Int. J. Impact Eng. 30, 367 (2004).

${ }^{10}$ J. M. Boteler and D. P. Dandekar, J. Appl. Phys. 100, 054902 (2006).

${ }^{11}$ R. Kaibyshev, F. Musin, E. Avtokratova, and Y. Motohash, Mater. Sci. Eng., A 392, 373 (2005).

${ }^{12}$ J. M. Boteler and D. P. Dandekar, in Shock Compression of Condensed Matter, edited by M. Elert, M. D. Furnish, R. Chau, N. Holmes, and J. Nguyen (AIP, New York, 2007), pp. 481-484.

${ }^{13}$ G. J. Appleby-Thomas, P. J. Hazell, J. Millett, and N. K. Bourne, in Shock Compression of Condensed Matter, edited by M. L. Elert, W. T. Buttler, M. D. Furnish, W. W. Anderson, and W. G. Proud (AIP, New York, 2009), pp. 533-536.

${ }^{14}$ ASM Aerospace Specifications Metals Inc, Aluminum 5083-H32; 5083H323, http://asm.matweb.com/search/SpecificMaterial.asp?bassnum $=$ MA5083H 32

${ }^{15}$ G. J. Appleby-Thomas, P. J. Hazell, C. Stennett, G. Cooper, K. Helaar, and A. M. Diederen, J. Appl. Phys. 105, 064916 (2009).

${ }^{16}$ J. E. Field, S. M. Walley, W. G. Proud, H. T. Goldrein, and C. R. Siviour, Int. J. Impact Eng. 30, 725 (2004).

${ }^{17}$ N. K. Bourne, Meas. Sci. Technol. 14, 273 (2003).

${ }^{18}$ Z. Rosenberg, D. Yaziv, and Y. Partom, J. Appl. Phys. 51, 3702 (1980).

${ }^{19}$ Z. Rosenberg and N. S. Brar, J. Appl. Phys. 77, 1443 (1995).

${ }^{20}$ J. C. F. Millett, N. K. Bourne, and Z. Rosenberg, J. Phys. D 29, 2466 (1996).

${ }^{21}$ ASM Handbook Committee, Metals Handbook, Metallography, Structures and Phase Diagrams, 8th ed. (American Society for Metals, Metals Park, Ohio, USA, 1973), Vol. 8.

${ }^{22}$ R. E. Winter and E. J. Harris, J. Phys. D 41, 035503 (2008).

${ }^{23}$ R. E. Winter, G. D. Owen, and E. J. Harris, J. Phys. D 41, 202006 (2008).

${ }^{24}$ G. J. Appleby-Thomas, P. J. Hazell, and C. Stennett, J. Mater. Sci. 44, 6187 (2009).

${ }^{25}$ J. C. F. Millett, N. K. Bourne, and D. P. Dandekar, J. Appl. Phys. 96, 3727 (2004).

${ }^{26}$ J. L. Brown and G. Ravichandran, in Shock Compression of Condensed Matter, edited by M. L. Elert, W. T. Buttler, M. D. Furnish, W. W. Anderson, and W. G. Proud (AIP, New York, 2009), pp. 747-750. 